\title{
Regulation of mRNA decay in plant responses to salt and osmotic stress
}

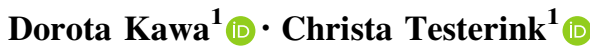

Received: 30 June 2016/Revised: 9 September 2016/Accepted: 21 September 2016/Published online: 27 September 2016

(C) The Author(s) 2016. This article is published with open access at Springerlink.com

\begin{abstract}
Plant acclimation to environmental stresses requires fast signaling to initiate changes in developmental and metabolic responses. Regulation of gene expression by transcription factors and protein kinases acting upstream are important elements of responses to salt and drought. Gene expression can be also controlled at the post-transcriptional level. Recent analyses on mutants in mRNA metabolism factors suggest their contribution to stress signaling. Here we highlight the components of mRNA decay pathways that contribute to responses to osmotic and salt stress. We hypothesize that phosphorylation state of proteins involved in mRNA decapping affect their substrate specificity.
\end{abstract}

Keywords Osmotic stress - Salinity - mRNA decay · mRNA decapping $\cdot$ mRNA stability .

$5^{\prime} \rightarrow 3^{\prime}$ exoribonucleases $\cdot$ SnRK2 kinases .

Protein phosphorylation · Posttranscriptional regulation ·

$\mathrm{P}$ bodies

\section{Emerging role of posttranscriptional level regulation in osmotic stress responses}

Plant survival under suboptimal conditions relies on the perception of environmental signals followed by signal transduction pathways leading to changes in gene expression to switch on protective mechanisms. Among the

Christa Testerink

c.s.testerink@uva.nl

1 Plant Cell Biology, Swammerdam Institute for Life Sciences, University of Amsterdam, Postbus 94215 , 1090 GE Amsterdam, The Netherlands abiotic stresses with a deleterious effect on plant development, salinity and osmotic stress are huge constrains for agriculture worldwide [1]. The decrease in osmotic potential of the soil that occurs both in saline soils and during drought leads to a reduction in water uptake by the plant. Plant adaptations to dehydration include stomatal closure, regulation of water fluxes and biosynthesis of osmoprotectants. To cope with salinity, in addition ion homeostasis needs to be adjusted [2,3]. Both salt stress and low water availability lead to alteration in shoot and root growth $[4,5]$. These physiological changes are guided through complex signal transduction pathways including $\mathrm{Ca}^{2+}$, reactive oxygen species and lipid signaling, abscisic acid (ABA) formation, sucrose-non-fermenting 1-related protein kinase 2 (SnRK2) and mitogen activated protein kinase (MAPK) activation, and transcription factor regulation $[2,4,6]$. Recent research has identified the regulatory networks of the osmotic stress-induced AREB/ $\mathrm{ABF}$ and DREB2A transcription factors (reviewed in $[7,8]$ ), and transcriptomic studies have identified many transcriptionally regulated candidates genes for osmotic and salt stress responses [9, 10]. However, abundance of mRNA depends not only on the control of transcription, but also on transcript degradation rate. Salt induced changes in Arabidopsis transcript abundance do not always correlate with observed changes in the proteome and most of the mRNAs for which abundance decreases on dehydration also show lower assembly with polysomes, suggesting posttranscriptional regulation of osmotic and salt stress responses $[11,12]$. Besides translation, another fate of transcribed mRNAs is to be subjected to mRNA decay or quality control pathways [13]. Increasing knowledge about factors regulating mRNA turnover in plants suggests their contribution to developmental processes [14-16] as well as stress responses [17]. Altered sensitivity to osmotic stress 
or salinity of mRNA decay machinery mutants [17], together with the short half-life time of transcripts involved in osmotic stress responses [18], suggests mRNA decay regulation to be an additional, important level of osmotic and salt stress signaling. Moreover, SnRK2 and MAP kinases known to be involved in salt and osmotic responses seem to interfere with mRNA stability pathways [19-22]. Here, we summarize current knowledge on mRNA metabolism contribution to drought and salt stress signaling and put these results into perspective of the action of already well-known players in these pathways (Fig. 1).

\section{Global mRNA stability under osmotic stress}

Many stress responsive genes, including ones involved in osmotic stress in human cells [23], yeast [24-27] and plants $[17,28,29]$ has been shown to be regulated by their mRNA stability. In yeast, the dynamics of global transcriptional rate after osmotic stress does not always match the changes in dynamics of mRNA abundance, which can be explained by global transcript destabilization [27]. Stability of mRNA was shown to depend on stress severity. Mild stress in general caused mRNA decay, while most osmotic stressresponsive mRNAs were stabilized, suggesting that regulation of mRNA turnover can affect specific subsets of transcripts. Severe osmotic shock resulted in global mRNA retention in processing bodies (P bodies), cytoplasmic foci where mRNA can be degraded or withheld from translation [27]. Decay of osmotic stress-induced mRNAs in yeast has been proposed to be essential in the recovery phase, to return to the base level of these mRNAs [30].

In Arabidopsis, mRNAs coding for proteins involved in responses to osmotic stress have been found among rapidly degraded transcripts [18]. Around $40 \%$ of mRNAs encoding sodium transporters were found in their uncapped version, implying that $5^{\prime} \rightarrow 3^{\prime}$ mRNA decay can also regulate responses to salt [31]. Global analysis of the transcriptome and degradome of Setaria italica revealed that also in this monocot species $5^{\prime} \rightarrow 3^{\prime}$ mRNA degradation is one of the mechanisms of responses to drought [32]. While control of mRNA stability in response to osmotic stress is receiving increasing attention, our knowledge of the mechanisms behind observed changes is still fragmentary.

\section{mRNA decay pathways in Arabidopsis}

Control of mRNA stability is an essential component of gene expression regulation. The rate of transcript degradation correlates with encoded function, and abundance of the transcript, number of introns and conserved sequences in the $5^{\prime}$ and $3^{\prime}$ UTR [18]. Arabidopsis mRNAs coding for transcription factors and protein kinases as well as transcripts targeted by microRNAs, and low abundance transcripts are in general unstable. Presence of at least one intron increases mRNA stability, and multiple stabilizing motifs within the UTRs' sequences have been identified [18]. Most transcripts appear in complex with proteins involved in translation initiation or mRNA decay and are constantly shifted between these two processes. Factors that activate the first steps of mRNA degradation in general repress translation and vice versa $[33,34]$. The mRNA decay machinery can target defective transcripts with premature stop codons or long $3^{\prime}$ UTR in nonsense-mediated decay (NMD), mRNA molecules without a stop codon in the process of non-stop decay (NSD), as well as transcripts that did not disassociate from ribosomes, by a mechanism known as non-go decay (NGD) (reviewed in [35, 36]). Besides degradation of abnormal transcripts, the mRNA decay machinery can also target mRNAs with a correct structure, serving as a regulatory step in gene expression [37]. The same enzymes are involved in mRNA degradation in specialized and general pathways (Fig. 1), but the recognition of substrates follows different mechanisms [37].

\section{First step—deadenylation}

In all eukaryotic organisms mRNA degradation starts by shortening the $3^{\prime}$ poly(A) tail [35]. This critical and ratelimiting step is guided by the deadenylases PARN, PAN and the CCR4/CAF1/NOT complex [38]. The poly(A) ribonuclease AtPARN catalyses deadenylation of a subset of embryonic transcripts in Arabidopsis, and lack of functional AtPARN results in embryo lethality [39, 40]. Expression of AtPARN is induced by ABA, osmotic and salt stress, while several AtPARN substrates were found to be degraded in both stress and control conditions [41]. Two Arabidopsis homologs of CARBON CATABOLYTE REPRESSOR4 (AtCCR4a and AtCCR4b) were shown to be involved in starch and sucrose metabolism [42, 43]. Eleven Arabidopsis CCR4-ASSOCIATED FACTOR1 (CAF1) genes have been found, among which AtCAF1a and AtCAF1b, which are associated with responses to multiple environmental stimuli, in most cases by non-redundantly targeting different mRNA subsets [44]. A mutant in AtCAF1a was able to germinate in the presence of salt and one-third of the transcripts upregulated in this mutant were salt-inducible, including one aldehyde dehydrogenase, ALDH7B4, which upon overexpression led to the same phenotype as the cafla mutant [44, 45]. Important to note is that the paralogous deadenylase AtCAF1b did not share a function in responses to salt, suggesting that similar enzymes with the same function can target different transcripts and thereby regulate other stress responses [44]. 


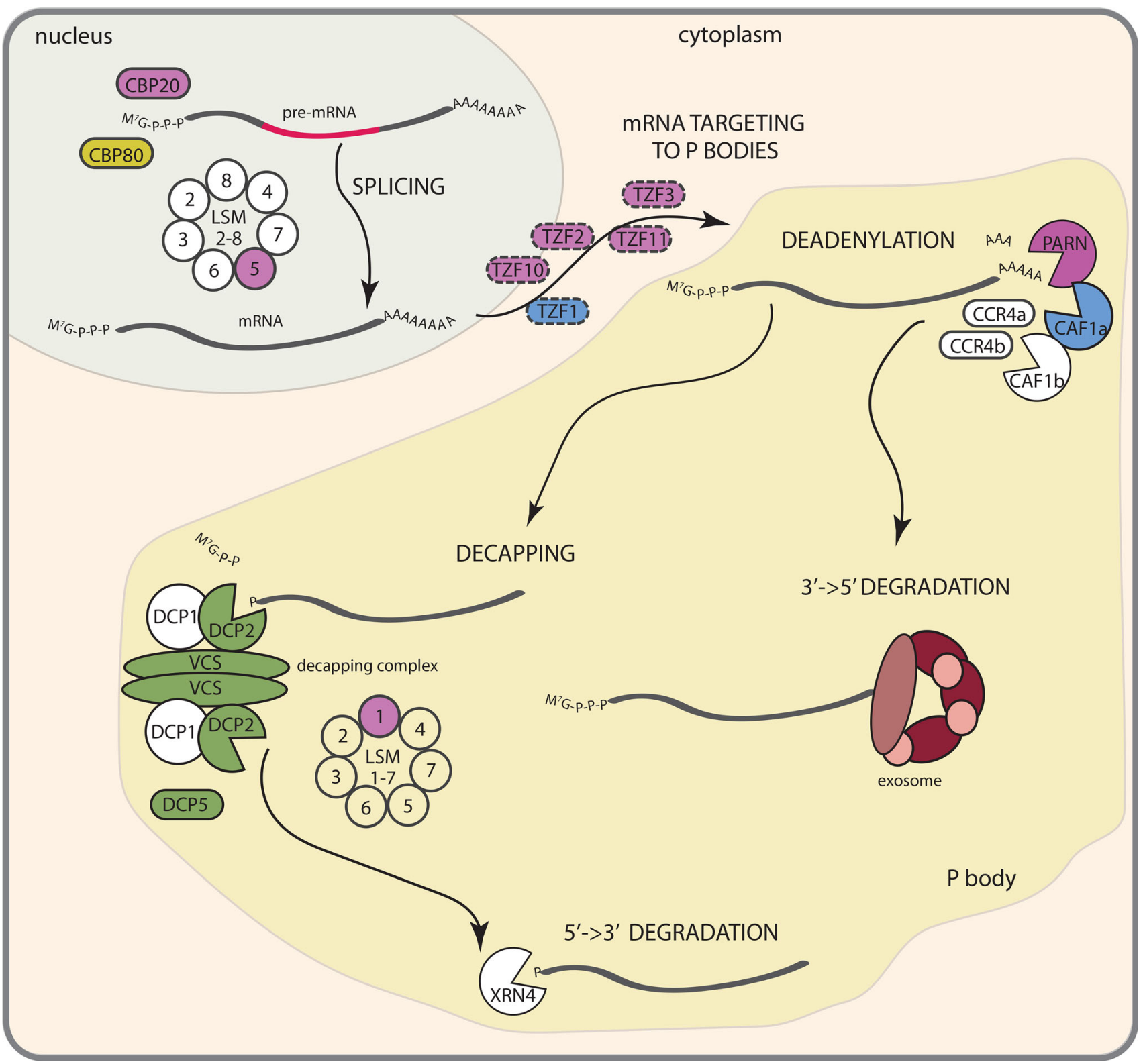

Fig. 1 Contribution of mRNA metabolism processes to plant responses to salinity and osmotic stress. Control of splicing occurs in the nucleus and is controlled by CBP20, CBP80 and the LSM2-8 complex. Targeting of specific transcript subsets to $\mathrm{P}$ bodies is hypothesized to be guided by TZF proteins. Cytoplasmic mRNA decay starts with deadenylation. After shortening the poly(A) tail, transcripts can be degraded from their $3^{\prime}$ end via the exosome

Neither the poly(A) nuclease PAN, that functions in deadenylation in humans and yeast, or other components of the CCR4/CAF1/NOT complex have been identified in Arabidopsis [37, 38].

\section{$3^{\prime} \rightarrow 5^{\prime}$ degradation}

Transcripts deprived of their poly(A) tail can be targeted to $3^{\prime}$ end decay catalyzed by the exosome, a multisubunit complex or undergo $5^{\prime}$ cap removal in a process of decapping followed by $5^{\prime} \rightarrow 3^{\prime}$ decay catalyzed by XRN4. Proteins marked in blue and green are involved in responses to salt and osmotic stress, respectively, purple color denotes factors involved in salt, osmotic and ABA signaling, while yellow indicates proteins responding to osmotic stress and ABA. Proteins for which function is only hypothetical are marked with dashed circles

complex involved in cytoplasmic mRNA degradation, and maturation of rRNA, snRNA and snoRNA in the nucleus [46]. The exosome is comprised of nine core subunits and associated cofactors including RNA-binding proteins and RNA helicases [37]. On the contrary to yeast and humans, the plant exosome core complex is self-activated through the phosphorolytic function of AtRRP41 (Arabidopsis thaliana homolog of Saccharomyces cerevisiae exosome subunit RRP41p) [47]. Mutations in exosome proteins 
result in early growth, female gametogenesis and embryogenesis defects [47-49], but so far no evidence has been reported for a role of the exosome machinery in osmotic stress signaling.

\section{$5^{\prime} \rightarrow 3^{\prime}$ degradation starts with decapping}

Deadenylated transcripts can be also directed to $5^{\prime} \rightarrow 3^{\prime}$ decay, where $5^{\prime}$ cap removal is the first step [13]. In Arabidopsis, this process is catalyzed by DECAPPING 2 (DCP2), acting in a complex with its activator DECAPPING 1 (DCP1), which does not have decapping activity itself. The DCP2-DCP1 interaction is crucial for $5^{\prime}$ cap removal and depends on VARICOSE (VCS) as a scaffolding protein [15]. Impaired function of decapping complex components results in severe developmental phenotypes, including cotyledon deformation or improper vein pattering, and lethality of homozygous knock-out (KO) mutants $[16,50]$. Decapping and further degradation take place in processing bodies ( $\mathrm{P}$ bodies), dynamic cytoplasmic foci concentrating mRNA decay enzymes, which depend on the supply of mRNA for their formation $[15,16,51]$. Besides the decapping machinery, another protein complex, consisting of LSM1-7 proteins, has been shown to serve as a decapping activator. Eight highly conserved SM-Like (LSM) proteins have been identified in Arabidopsis, which via specific interactions with each other, form two separate heptameric complexes: cytoplasmic LSM1-7 and nuclear LSM2-8, the latter functioning in splicing events [52, 53]. LSM 2, LSM3, LSM4, LSM5, LSM6 and LSM7 are present both in cytoplasm and nucleus, while LSM1 and LSM8 localization is restricted to cytoplasm and nucleus, respectively [52]. Two duplicated functionally redundant genes, $L S M 1 A$ and $L S M 1 B$, encode for the LSM1 protein $[52,53]$. In an lsmla lsmlb double mutant decapping and decay rates of transcripts was decreased [28, 52]. Another protein carrying an LSM domain, DCP5, was shown to promote decapping without affecting DCP2 activity [54]. The formation of P bodies was altered in both $d c p 5$ and $l s m 1 a$ lsmlb mutants, suggesting that DCP5 and the LSM1-7 complex may indirectly activate decapping via $\mathrm{P}$ body assembly $[52,54]$. Two other LSM proteins, LSM4 and LSM5/SUPERSENSITIVE TO ABA AND DROUGHT 1 (SAD1), have been described only for their role in splicing processes so far $[53,55,56]$.

While proper functioning of the decapping complex is required for basal plant development, an increasing amount of evidence suggests it may also be involved in stress responses [22, 28, 29, 52]. Stability of osmotic and saltresponsive transcripts appears to be regulated via DCP1 and its interaction with other proteins. Within 15 min upon dehydration, MAP kinase 6 (MPK6) is activated and phosphorylates DCP1. Phosphorylation of DCP1 then triggers DCP1 dimerization and association with DCP2 and DCP5. Increased assembly and activity of the decapping complex stabilizes mRNAs encoding for signal transduction components, transcription factors and nucleic acid binding factors and induces decay of transcripts involved in lipid metabolism and nutrient balance [22]. Among the stabilized transcription factors, DREB2b is also induced by osmotic stress and high salinity [57], indicating that dehydration not only triggers expression of DREB2b transcript, but also protects it from the decay. DCP1 has also been shown to physically interact with the BEACH (beige and Chedial Higashi) domain protein SPIRRIG (SPI) [29]. Arabidopsis SPI, known previously to participate in maintenance of membrane integrity, was recruited to $\mathrm{P}$ bodies upon interaction with DCP1 [29, 58]. A spi mutant showed less $\mathrm{P}$ body formation upon salt stress, and was hypersensitive to salt [29]. SPI triggered the recruitment of a subset of salt-responsive mRNAs and ribonucleoprotein (RNP) assembly critical for P body formation. Together this suggests that under stress conditions activity of DCP1 can be modulated by interaction with MPK6 and SPI.

LSM1, one of the components of the decapping activator complex LSM1-7, was also found to guide responses to salt and drought stress. The lsmla lsmlb mutant has altered levels of both hormonal signaling and stress defense transcripts [53]. Interestingly, lsmla lsmlb plants showed a higher survival after drought in soil experiments and higher fresh weight and number of lateral roots on osmotic stress applied in agar media [28]. On the other hand, in the presence of salt, overall growth of $l s m l a l s m l b$ seedlings was severely inhibited, suggesting their hypersensitivity to salt. Transcriptome analysis revealed that in the lsmla $l s m 1 b$ mutant exposed to osmotic stress, transcripts encoding positive factors for drought tolerance were stabilized (e.g. ABR1, ANAC019, ERF53), while salt stress led to stabilization of mRNAs of negative regulators of salinity tolerance (e.g. ANAC092, AHK5, ATGSTU17). One of the mRNAs stabilized specifically on salt was the ABA biosynthesis gene $N C E D 3$, indicating involvement of the decapping machinery in $\mathrm{ABA}$ biosynthesis in response to salinity. LSM1 is also crucial for formation of $\mathrm{P}$ bodies in osmotic or salt stress conditions. By guiding its target mRNAs to P bodies, activating their decapping and thus exposing them to degradation, LSM1 regulates sensitivity to osmotic stress and salinity [28]. Via the same processes, LSM1 regulates not only responses to drought and salinity, but also to cold stress [28]. Different stress signaling pathways target different mRNAs, yet the mechanism of this selectivity remains unknown. 


\section{$5^{\prime} \rightarrow 3^{\prime}$ cleavage}

The naked mRNA molecule is an easy target for $5^{\prime} \rightarrow 3^{\prime}$ exoribonucleases. While three of these have been identified in Arabidopsis, only XRN4 localizes to the cytoplasm and can target decapped mRNAs [59]. Surprisingly only a small subset of transcripts has an altered decay rate in the $x r n 4$ mutant and none of the previously identified highly unstable mRNAs were targets of XRN4, suggesting existence of other plant $5^{\prime} \rightarrow 3^{\prime}$ exoribonucleases $[18,60]$. Substrate selectivity of XRN4 was linked to the presence of hexamer motifs in the $5^{\prime}$ end of its targets [61]. Decapped transcripts can be also targets of RNA-dependent RNA polymerases and in this way induce gene silencing [62]. A subset of XRN4 substrates appears to be derived from miRNA cleavage, suggesting the existence of two mechanisms of XRN4 action: via general cytoplasmic $5^{\prime} \rightarrow 3^{\prime}$ decay and by decay of miRNA degradation products [60]. On the contrary to mutants in decapping machinery components, xrn 4 mutants do not have any developmental alterations, but are insensitive to ethylene, show higher tolerance to heat stress and exhibit decreased sensitivity to auxin with respect to lateral root formation [63-65]. In xrn 4 mutants, levels of $E B F 1$ and $E B F 2$ mRNA, encoding F-box proteins that participate in degradation of the major transcriptional regulator of ethylene signaling EIN3, was decreased. $E B F$ RNA decay rates were not altered, suggesting they are indirect targets $[63,66]$. In addition, abundance of many other transcripts was decreased in the xrn4 mutant, suggesting that XRN4 can affect transcripts level not only via its exoribonucleic activity, but also indirectly [61].

Through direct degradation of mRNA of heat shock factor A2 (HSFA2), XRN4 is involved in suppression of heat stress responses after return to normal temperature [64]. While the $x r n 4$ mutant was more tolerant to short and severe heat stress, a very low level of thermotolerance was observed to moderately high temperatures, possibly caused by separate subsets of mRNAs being targeted at different stress intensities [64, 67]. Interestingly, upon heat stress XRN4 interacts with LARP1, a homolog of human RNAbinding protein, and in this complex XRN4 is directed to polysomes $[67,68]$. A proportion of the transcripts rapidly degraded upon heat stress is subjected to XRN4-dependent $5^{\prime} \rightarrow 3^{\prime}$ decay while still being associated to elongating polysomes, supporting the concept of co-translational $5^{\prime} \rightarrow 3^{\prime}$ decay, suggested previously to occur in yeast and Arabidopsis [67, 69, 70]. Co-translational mRNA decay was shown to be involved in salt stress signaling in yeast, and this function might be conserved in plant responses to salinity $[71,72]$.

\section{Role of nuclear mRNA metabolism regulators in salt and osmotic stress signaling}

In parallel to regulators of cytoplasmic RNA metabolism, nuclear pre-mRNA processing enzymes also appear to be involved in responses to osmotic stress. Hypersensitivity to salinity of sadl/lsm 5 and $l s m 4$, mutants in the nuclear LSM2-8 complex for intron removal, suggests involvement of the splicing machinery in salt stress responses $[55,56,73]$. SAD1 is essential for accurate splice site recognition and splicing efficiency. Overexpression of SAD1/LSM5 led to an increase in properly spliced transcripts of $C I P K 3, A B F 3$, and DREB2A, and improved salt tolerance. Aberrant splicing events of transcripts involved in salinity responses were found in sad1/lsm5 plants exposed to salt stress [56]. A sadl/lsm4 point mutation did not affect global gene expression, but expression of many transcripts of ABA biosynthesis and signaling pathway factors decreased [73]. Two nuclear cap-binding proteins CBP80 and CBP20 have been shown to regulate alternative splicing of transcripts coding for the auxin response factors ARF10 and ARF17, as well as for proline and sugar metabolism factors [74]. The $\operatorname{cbp} 80$ and $\operatorname{cbp} 20$ mutants both had higher sensitivity to salt and ABA and cbp20 showed decreased stomatal conductance and sensitivity to water withdrawal [74, 75]. Cbp80/abhl mutants also had decreased levels of $P P 2 C$ phosphatase transcripts involved in ABA signal transduction, which could explain its $\mathrm{ABA}$ hypersensitivity [76]. Abscisic acid (ABA) is a phytohormone with a crucial role in salt and drought signaling [77]. Both ABA biosynthesis and its signaling pathways seem to be regulated at the level of pre-mRNA splicing (also reviewed in [78]). Another nuclear protein, the mRNA capping enzyme family protein At5G28210, was mapped recently as a putative gene involved in root growth in the presence of a combination of salt and phosphate starvation [79].

\section{Small RNA-mediated regulation of mRNA decay}

Another level of regulation of gene expression in plants is RNA interference (RNAi) in which a micro RNA (miRNA), through the RNA-induced silencing complex (RISC) can guide the cleavage of a target mRNA [80]. Products of miRNA cleavage are then degraded by XRN4 [60]. On the other hand, XRN4 acts antagonistically with RNAi processes because endonucleolytic cleavage of uncapped mRNA removes template for RNA-dependent RNA polymerases [62]. Accumulation of these transcripts in an $x r n 4$ mutant leads to excessive gene silencing [62]. Nuclear $5^{\prime} \rightarrow 3^{\prime}$ exoribonucleases XRN2 an XRN3 suppress 
posttranscriptional gene silencing by degradation of the loops that are excised from a pri-miRNA during its maturation [81]. Moreover, numerous miRNAs are involved in responses to osmotic stress or salinity $[82,83]$ and multiple proteins participating in miRNA biogenesis are also implicated in responses to salt, osmotic stress or ABA [84].

\section{TZF proteins}

Another group of proteins putatively involved in regulation of salt and osmotic stress responses at the posttranscriptional level are tandem $\mathrm{CCCH}$ zinc finger proteins (TZFs) $[85,86]$. Mammalian TZFs are able to bind to ARE elements, AU-rich sequences at the $3^{\prime}$ end of mRNA molecules, and this interaction recruits enzymes involved in deadenylation, decapping and exonucleolitic cleavage $[87,88]$. Evidence increases that plant TZF proteins may be also involved in mRNA turnover control. Arabidopsis TZF1 and TZF9 and rice OsTZF1 possess RNA binding capacity [89, 90], while TZF2 and TZF3 exhibit RNAse activity [91]. So far the contribution of plant TZFs to mRNA decay has been shown only for TZF1, which can induce degradation of ARE-containing transcripts [92].

Expression of Arabidopsis TZF1 is triggered by salt only, while TZF2, TZF3, TZF10 and TZF11 are induced by salinity, osmotic stress and ABA [91, 93]. Overexpression of TZF10 or TZF11 led to increased salt tolerance and decreased expression of RD29A and KIN1 [93]. Overexpression lines of TZF2 and TZF3 showed higher drought tolerance and reduced water loss than wild type plants [91]. Moreover, induction of TZF3 resulted in decreased expression of $\mathrm{ABI} 2$, while a $t z f 3$ knock-out mutant was hypersensitive to both salt stress and ABA [94]. Rice OsTZF1 relocalised to $\mathrm{P}$ bodies upon salt stress or ABA treatment and its overexpression conferred faster recovery from salinity or drought [89]. Osmotic stress-induced cotton GhZFP1 is involved in adaptation to salinity and its overexpression led to high potassium/sodium ratio. Similar to mammalian TZFs, plant TZFs can shuttle between nucleus and cytoplasm and localize to P bodies and stress granules $[89,90,95,96]$. Importantly, altered expression of TZFs affects usually a subset of transcripts [91, 93, 94]. Specificity of mRNA metabolism processes that occur in $\mathrm{P}$ bodies may rely on TZF proteins binding to cis-elements in mRNA [17]. Interestingly, $\mathrm{Y} 2 \mathrm{H}$ analysis revealed that TZF5 interacts with MARD1 and RD21A, proteins involved in $\mathrm{ABA}$ and dehydration responses, but not with any of the components of mRNA decay machinery [96]. This may suggest that additional interactions with stressinduced proteins may be also required for osmotic and salt regulation at the level of mRNA metabolism.

\section{Emerging role of protein kinases in mRNA stability regulation}

The aforementioned factors involved at different stages of mRNA stability can guide responses to multiple stresses by selective targeting of subsets of transcripts [22, 28, 29]. The mechanism of this stress-dependent control of differential gene expression remains unclear, but increasing recent evidence suggests that decapping factors are phosphorylated upon stress exposure. In response to osmotic stress, human DCP1a is phosphorylated by c-Jun N-terminal kinase (JNK) and targeted to P bodies [97]. In glucose-deprived yeast, the protein kinase Ste20 phosphorylates DCP2 and stabilizes the DCP1-DCP2 interaction [98]. Yeast mRNA stability upon exposure to osmotic stress is dependent on the MAP kinase Hog1, via an unknown mechanism [27] (Fig. 2).

In Arabidopsis, MPK6 is involved in phosphorylation of DCP1 in response to drought stress, while upon flagellin treatment MAP kinase 4 (MPK4) phosphorylates PAT1, another activator of decapping [22, 99]. The MPK phosphorylation motif was also found in the decapping activator LSM1, which could explain its stress-dependent substrate specificity [28]. A phosphoproteomics study revealed that DCP2 phosphorylation increases in response to osmotic stress, but the kinase catalyzing this process still remains to be identified [20] (Fig. 2).

Another member of the decapping complex, VCS, was also differentially phosphorylated upon osmotic and salt stress, but not after ABA treatment [20, 21]. The phosphorylated version of VCS was downregulated in a triple KO mutant of ABA-dependent protein kinases, the snrk2.2/ 2.3/2.6 mutant, while VCS phosphorylation was lower upon ABA treatment, suggesting it could be an indirect target of SnRK2.2/SnRK2.3/SnRK2.6 [21]. Phosphorylation of multiple individual Ser residues of VCS was either enhanced or inhibited by mannitol treatment, reflecting the complicated nature of this regulation [20]. Together, this evidence suggests that differential phosphorylation of decapping factors upon osmotic or salt stress could enable them to target only a subset of transcripts. Since cytoplasmic $5^{\prime} \rightarrow 3^{\prime}$ mRNA decay, starting with $5^{\prime}$ cap removal, occurs also in control conditions it is plausible that under osmotic stress conditions decapping activity and substrate selectivity is regulated in a different way. Evidence is accumulating for a role of post-translational modifications, including phosphorylation, in regulation of this process.

Recent phosphoproteomics studies [20, 21] have revealed upregulation of phosphorylated forms of SnRK2.1/4/5/6/10, MAP3K Raf18, MAP4K $\alpha 1$ and DCP2 within 5 min after osmotic stress treatment. Nine out of ten Arabidopsis SnRK2 protein kinases are rapidly activated 


\section{human}

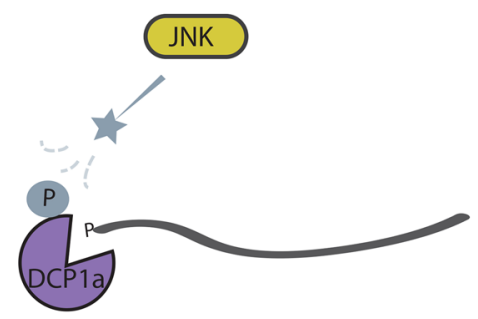

yeast

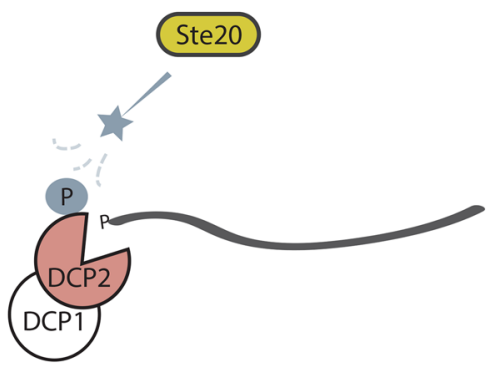

plant

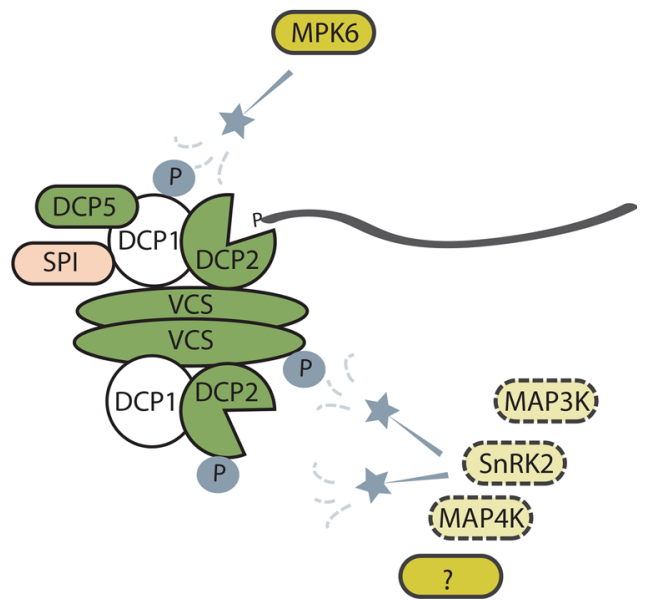

Fig. 2 Involvement of protein kinases in regulation of mRNA decapping processes. In human cells protein kinase JNK phosphorylates DCP1a and through this regulates P body formation. In yeast, upon glucose deprivation Ste20 phosphorylates DCP2 to stabilize its interaction with DCP1. In Arabidopsis MPK6 is activated by drought and phosphorylates DCP1, thus inducing DCP1 interactions with

by osmotic stress, while activity of SnRK2.2, SnRK2.3 and SnRK2.6 is also regulated by ABA [100]. SnRK2.6 has been shown to phosphorylate the anion channel SLAC1 [101, 102], potassium channel KAT1 [103], AtrbohF NADPH oxidase [104], transcription factor ABARESPONSIVE ELEMENT BINDING PROTEIN 3 (AREB3) [19] and aquaporin PLASMA MEMBRANE INTRINSIC PROTEIN (PIP2;1) [105]. All SnRK2 subclass 2 and 3 can phosphorylate the transcription factor AREB1 [106]. Contrary to ABA-dependent SnRK2s, targets of SnRK2 subclass 1 protein kinases,remain to be identified. Whether these kinases or MAP3Ks/MAP4Ks can directly or indirectly target DCP2 remains unknown (Fig. 2).

It is unknown whether activity of plant DCP2 depends on its phosphorylation status, or is possibly triggered by phosphorylation of DCP1 or VCS, and finally whether phosphorylation of DCP1, DCP2 and VCS influences their relocalisation to $\mathrm{P}$ bodies or assembly of decapping complex. To address these questions, protein kinases targeting these proteins need to be identified. For SnRK2.6, no subcellular localization data are available, but the subclass 1 SnRK2.4 and a Medicago stress induced MAP2K (SIMKK) have been shown to localize to punctate structures after exposure of roots to salt [107, 108]. Yet, it remains to be established whether these would be $\mathrm{P}$ bodies or in case of SnRK2.4, would reflect lipid binding capacity [109]. Finally, it should be noted that phosphorylated
DCP2 and DCP5. Upon salt stress, SPI protein binds to DCP1 and facilitate its recruitment to P bodies. Phosphorylation of DCP2 and VCS is triggered by osmotic stress, but kinases functioning upstream remain still unknown. Phosphoproteomic profiling studies may suggest involvement of SnRK2 or MAP kinases in this process

versions of DCP1 and VCS have also been detected in control conditions, so any putative regulation by protein kinases in response to osmotic stress may have a quantitative character [20, 22].

Several proteins involved in pre-mRNA processing and splicing have been found as putative targets of ABA-dependent SnRK2 kinases [19, 21, 110], implying that proteins involved in nuclear mRNA metabolism can be also regulated by phosphorylation. Altered ABA sensitivity of sad1/lsm5, lsm4, cbp20, cbp80/abhl, and ahg2-1 mutants suggests they function via adjustment of hormonal signaling pathways $[41,55,73,74,76]$.

The mRNA decapping step takes place in $\mathrm{P}$ bodies, meaning that salt- and osmotic-dependent mRNA degradation relies on proper assembly of RNP particles and recruitment of all their components to $\mathrm{P}$ bodies. So far it is not known how mRNAs targeted for degradation relocate to $\mathrm{P}$ bodies and whether the process would involve interactions with RNA-binding proteins, decapping factors or other stress-induced proteins. The salt responsive protein SPI does not possess RNA-binding capacity but seems to regulate uptake of mRNA into P bodies and RNP formation via an unknown mechanism [29]. The LSM1 protein physically interacts not only with members of the LSM1-7 complex, but was also co-purified with some stress-responsive proteins without RNA-binding properties [53]. It would be of interest to investigate whether osmotic- and salt stress can induce interaction of decapping factors with 
SnRK2 kinases, MAP4K $\alpha 1$, MAP3K Raf18, MPK6 or SPI and how this would modify their function.

Another possibility is that substrate selectivity of the decapping machinery depends on the abundance of targeted mRNAs, as was shown for some of the transcripts for which degradation is triggered by LSM1 [28]. Finally, specificity could also depend on the mobility of selectively targeted mRNAs. Regulation of mRNA transport from nucleus to cytoplasm is relatively well known, but the mechanism of transcript mobility in the cytoplasm and recruitment to $\mathrm{P}$ bodies still remains unknown [111]. RNA binding capacity of TZFs that shuttle between nucleus, cytoplasm and $\mathrm{P}$ bodies together with their role in tolerance to osmotic and salt stress [85] suggests that their interaction with a specific subset of transcripts could be a possible mechanism to regulate their loading to $\mathrm{P}$ bodies [17, 89, 90, 93, 94].

\section{Conclusions}

Several factors controlling mRNA metabolism are involved in osmotic or salt stress responses of plants. Most of these are involved in mRNA decapping and as a consequence in $5^{\prime} \rightarrow 3^{\prime}$ decay of transcripts. The contribution of other factors may be indirect, for example CAF1a could function by promoting deadenylation, inducing decapping in a similar way as in yeast [112]. Interestingly, most of the factors discussed here are involved in regulation of multiple stresses, but target only a condition-specific subset of transcripts [17, 28, 41, 63]. Unraveling the mechanism of this selectivity would be of high importance. Here, we propose posttranslational modification of mRNA decay factors as a possible mechanism of substrate selectivity. Multiple phosphorylation sites have been identified in several mRNA metabolism regulators, which appear to be phosphorylated in response to osmotic and salt stress in a quantitative.way. Further characterization of osmotic- and salt-induced targets of $5^{\prime} \rightarrow 3^{\prime}$ decay pathways is also necessary. We propose here that changes in gene expression upon osmotic and salt stress should be studied not only at the transcriptome level, but should be extended to the posttranscriptional level.

Acknowledgments This work was supported by the Netherlands Organisation for Scientific Research (NWO-NSFC Project ALW846.11.002).

Open Access This article is distributed under the terms of the Creative Commons Attribution 4.0 International License (http:// creativecommons.org/licenses/by/4.0/), which permits unrestricted use, distribution, and reproduction in any medium, provided you give appropriate credit to the original author(s) and the source, provide a link to the Creative Commons license, and indicate if changes were made.

\section{References}

1. Fita A, Rodriguez-Burruezo A, Boscaiu M, Prohens J, Vicente O (2015) Breeding and Domesticating crops adapted to drought and salinity: a new paradigm for increasing food production. Front Plant Sci 6:978. doi:10.3389/fpls.2015.00978

2. Golldack D, Li C, Mohan H, Probst N (2014) Tolerance to drought and salt stress in plants: unraveling the signaling networks. Front Plant Sci 5:151. doi:10.3389/fpls.2014.00151

3. Hasegawa PM (2013) Sodium $\left(\mathrm{Na}^{+}\right)$homeostasis and salt tolerance of plants. Environ Exp Bot 92:19-31. doi:10.1016/j. envexpbot.2013.03.001

4. Julkowska MM, Testerink C (2015) Tuning plant signaling and growth to survive salt. Trends Plant Sci 20(9):586-594. doi:10. 1016/j.tplants.2015.06.008

5. Pierik R, Testerink C (2014) The art of being flexible: how to escape from shade, salt, and drought. Plant Physiol 166(1):5-22. doi:10.1104/pp.114.239160

6. McLoughlin F, Testerink C (2013) Phosphatidic acid, a versatile water-stress signal in roots. Front Plant Sci 4:525. doi:10.3389/ fpls.2013.00525

7. Fujita Y, Yoshida T, Yamaguchi-Shinozaki K (2013) Pivotal role of the AREB/ABF-SnRK2 pathway in ABRE-mediated transcription in response to osmotic stress in plants. Physiol Plant 147(1):15-27. doi:10.1111/j.1399-3054.2012.01635.x

8. Yoshida T, Mogami J, Yamaguchi-Shinozaki K (2014) ABAdependent and ABA-independent signaling in response to osmotic stress in plants. Curr Opin Plant Biol 21:133-139. doi:10.1016/j.pbi.2014.07.009

9. Kreps JA, Wu Y, Chang HS, Zhu T, Wang X, Harper JF (2002) Transcriptome changes for Arabidopsis in response to salt, osmotic, and cold stress. Plant Physiol 130(4):2129-2141. doi:10.1104/pp.008532

10. Rasheed S, Bashir K, Matsui A, Tanaka M, Seki M (2016) Transcriptomic analysis of soil-grown Arabidopsis thaliana roots and shoots in response to a drought stress. Front Plant Sci 7:180. doi:10.3389/fpls.2016.00180

11. Kawaguchi R, Girke T, Bray EA, Bailey-Serres J (2004) Differential mRNA translation contributes to gene regulation under non-stress and dehydration stress conditions in Arabidopsis thaliana. Plant J 38(5):823-839. doi:10.1111/j.1365-313X.2004. 02090.X

12. Jiang Y, Yang B, Harris NS, Deyholos MK (2007) Comparative proteomic analysis of $\mathrm{NaCl}$ stress-responsive proteins in Arabidopsis roots. J Exp Bot 58(13):3591-3607. doi:10.1093/jxb/ erm207

13. Belostotsky DA, Sieburth LE (2009) Kill the messenger: mRNA decay and plant development. Curr Opin Plant Biol 12(1):96-102. doi:10.1016/j.pbi.2008.09.003

14. Xu J, Chua NH (2011) Processing bodies and plant development. Curr Opin Plant Biol 14(1):88-93. doi:10.1016/j.pbi.2010. 10.003

15. Xu J, Yang JY, Niu QW, Chua NH (2006) Arabidopsis DCP2, DCP1, and VARICOSE form a decapping complex required for postembryonic development. Plant Cell 18(12):3386-3398. doi:10.1105/tpc.106.047605

16. Goeres DC, Van Norman JM, Zhang W, Fauver NA, Spencer ML, Sieburth LE (2007) Components of the Arabidopsis mRNA decapping complex are required for early seedling development. Plant Cell 19(5):1549-1564. doi:10.1105/tpc.106.047621

17. Maldonado-Bonilla LD (2014) Composition and function of $P$ bodies in Arabidopsis thaliana. Front Plant Sci 5:201. doi:10. 3389/fpls.2014.00201

18. Narsai R, Howell KA, Millar AH, O'Toole N, Small I, Whelan J (2007) Genome-wide analysis of mRNA decay rates and their 
determinants in Arabidopsis thaliana. Plant Cell 19(11):3418-3436. doi:10.1105/tpc.107.055046

19. Wang P, Xue L, Batelli G, Lee S, Hou YJ, Van Oosten MJ, Zhang H, Tao WA, Zhu JK (2013) Quantitative phosphoproteomics identifies SnRK2 protein kinase substrates and reveals the effectors of abscisic acid action. Proc Natl Acad Sci USA 110(27):11205-11210. doi:10.1073/pnas.1308974110

20. Stecker K, Minkoff BB, Sussman MR (2014) Phosphoproteomic analyses reveal early signaling events in the osmotic stress response. Plant Physiol 165(3):1171-1187. doi:10.1104/pp.114. 238816

21. Umezawa T, Sugiyama N, Takahashi F, Anderson JC, Ishihama Y, Peck SC, Shinozaki K (2013) Genetics and phosphoproteomics reveal a protein phosphorylation network in the abscisic acid signaling pathway in Arabidopsis thaliana. Sci Signal 6 (270):rs8. doi:10.1126/scisignal.2003509

22. Xu J, Chua NH (2012) Dehydration stress activates Arabidopsis MPK6 to signal DCP1 phosphorylation. EMBO J 31(8):1975-1984. doi:10.1038/emboj.2012.56

23. Fan J, Yang X, Wang W, Wood WH 3rd, Becker KG, Gorospe M (2002) Global analysis of stress-regulated mRNA turnover by using cDNA arrays. Proc Natl Acad Sci USA 99(16):10611-10616. doi:10.1073/pnas.162212399

24. Greatrix BW, van Vuuren HJ (2006) Expression of the HXT13, HXT15 and HXT17 genes in Saccharomyces cerevisiae and stabilization of the HXT1 gene transcript by sugar-induced osmotic stress. Curr Genet 49(4):205-217. doi:10.1007/s00294005-0046-x

25. Gowrishankar G, Winzen R, Bollig F, Ghebremedhin B, Redich N, Ritter B, Resch K, Kracht M, Holtmann H (2005) Inhibition of mRNA deadenylation and degradation by ultraviolet light. Biol Chem 386(12):1287-1293. doi:10.1515/BC.2005.146

26. Hilgers V, Teixeira D, Parker R (2006) Translation-independent inhibition of mRNA deadenylation during stress in Saccharomyces cerevisiae. RNA 12(10):1835-1845. doi:10.1261/rna. 241006

27. Romero-Santacreu L, Moreno J, Perez-Ortin JE, Alepuz P (2009) Specific and global regulation of mRNA stability during osmotic stress in Saccharomyces cerevisiae. RNA 15(6):1110-1120. doi:10.1261/rna.1435709

28. Perea-Resa C, Carrasco-Lopez C, Catala R, Tureckova V, Novak O, Zhang W, Sieburth L, Jimenez-Gomez JM, Salinas J (2016) The LSM1-7 complex differentially regulates Arabidopsis tolerance to abiotic stress conditions by promoting selective mRNA decapping. Plant Cell 28(2):505-520. doi:10. 1105/tpc. 15.00867

29. Steffens A, Bräutigam A, Jakoby M, Hülskamp M (2015) The BEACH domain protein SPIRRIG is essential for Arabidopsis salt stress tolerance and functions as a regulator of transcript stabilization and localization. PLoS Biol 13(7):e1002188. doi:10.1371/journal.pbio.1002188

30. Molin C, Jauhiainen A, Warringer J, Nerman O, Sunnerhagen P (2009) mRNA stability changes precede changes in steady-state mRNA amounts during hyperosmotic stress. RNA 15(4):600-614. doi:10.1261/rna.1403509

31. Jiao Y, Riechmann JL, Meyerowitz EM (2008) Transcriptomewide analysis of uncapped mRNAs in Arabidopsis reveals regulation of mRNA degradation. Plant Cell 20(10):2571-2585. doi:10.1105/tpc. 108.062786

32. Yi F, Chen J, Yu J (2015) Global analysis of uncapped mRNA changes under drought stress and microRNA-dependent endonucleolytic cleavages in foxtail millet. BMC Plant Biol 15:241. doi:10.1186/s12870-015-0632-0

33. Coller J, Parker R (2005) General translational repression by activators of mRNA decapping. Cell 122(6):875-886. doi:10. 1016/j.cell.2005.07.012
34. Schwartz DC, Parker R (1999) Mutations in translation initiation factors lead to increased rates of deadenylation and decapping of mRNAs in Saccharomyces cerevisiae. Mol Cell Biol 19(8):5247-5256

35. Doma MK, Parker R (2007) RNA quality control in eukaryotes. Cell 131(4):660-668. doi:10.1016/j.cell.2007.10.041

36. Garneau NL, Wilusz J, Wilusz CJ (2007) The highways and byways of mRNA decay. Nat Rev Mol Cell Biol 8(2):113-126. doi: $10.1038 / \mathrm{nrm} 2104$

37. Parker R, Song H (2004) The enzymes and control of eukaryotic mRNA turnover. Nat Struct Mol Biol 11(2):121-127. doi:10. 1038/nsmb724

38. Abbasi N, Park Y-I, Choi S-B (2013) RNA deadenylation and decay in plants. J Plant Biol 56(4):198-207. doi:10.1007/ s12374-013-0201-8

39. Chiba Y, Johnson MA, Lidder P, Vogel JT, van Erp H, Green PJ (2004) AtPARN is an essential poly(A) ribonuclease in Arabidopsis. Gene 328:95-102. doi:10.1016/j.gene.2003.11.028

40. Reverdatto SV, Dutko JA, Chekanova JA, Hamilton DA, Belostotsky DA (2004) mRNA deadenylation by PARN is essential for embryogenesis in higher plants. RNA 10(8):1200-1214. doi:10.1261/rna.7540204

41. Nishimura N, Kitahata N, Seki M, Narusaka Y, Narusaka M, Kuromori T, Asami T, Shinozaki K, Hirayama T (2005) Analysis of ABA hypersensitive germination2 revealed the pivotal functions of PARN in stress response in Arabidopsis. Plant $\mathbf{J}$ 44(6):972-984. doi:10.1111/j.1365-313X.2005.02589.x

42. Suzuki Y, Arae T, Green PJ, Yamaguchi J, Chiba Y (2015) AtCCR4a and AtCCR4b are involved in determining the poly(A) length of granule-bound starch synthase 1 transcript and modulating sucrose and starch metabolism in Arabidopsis thaliana. Plant Cell Physiol 56(5):863-874. doi:10.1093/pcp/ pcv012

43. Dupressoir A, Morel A-P, Barbot W, Loireau M-P, Corbo L, Heidmann T (2001) Identification of four families of yCCR4and $\mathrm{Mg}^{2+}$-dependent endonuclease-related proteins in higher eukaryotes, and characterization of orthologs of yCCR4 with a conserved leucine-rich repeat essential for hCAF1/hPOP2 binding. BMC Genom 2(1):1-14. doi:10.1186/1471-2164-2-9

44. Walley JW, Kelley DR, Nestorova G, Hirschberg DL, Dehesh K (2010) Arabidopsis deadenylases AtCAF1a and AtCAF1b play overlapping and distinct roles in mediating environmental stress responses. Plant Physiol 152(2):866-875. doi:10.1104/pp.109. 149005

45. Kotchoni SO, Kuhns C, Ditzer A, Kirch HH, Bartels D (2006) Over-expression of different aldehyde dehydrogenase genes in Arabidopsis thaliana confers tolerance to abiotic stress and protects plants against lipid peroxidation and oxidative stress. Plant Cell Environ 29(6):1033-1048

46. Chlebowski A, Lubas M, Jensen TH, Dziembowski A (2013) RNA decay machines: the exosome. Biochim Biophys Acta 1829(6-7):552-560. doi:10.1016/j.bbagrm.2013.01.006

47. Chekanova JA, Shaw RJ, Wills MA, Belostotsky DA (2000) Poly(A) tail-dependent exonuclease AtRrp41p from Arabidopsis thaliana rescues 5.8 S rRNA processing and mRNA decay defects of the yeast ski6 mutant and is found in an exosomesized complex in plant and yeast cells. J Biol Chem 275(42):33158-33166. doi:10.1074/jbc.M005493200

48. Chekanova JA, Gregory BD, Reverdatto SV, Chen H, Kumar R, Hooker T, Yazaki J, Li P, Skiba N, Peng Q, Alonso J, Brukhin V, Grossniklaus U, Ecker JR, Belostotsky DA (2007) Genomewide high-resolution mapping of exosome substrates reveals hidden features in the Arabidopsis transcriptome. Cell 131(7):1340-1353. doi:10.1016/j.cell.2007.10.056

49. Yang M, Zhang B, Jia J, Yan C, Habaike A, Han Y (2013) RRP41L, a putative core subunit of the exosome, plays an 
important role in seed germination and early seedling growth in Arabidopsis. Plant Physiol 161(1):165-178. doi:10.1104/pp.112. 206706

50. Deyholos MK, Cavaness GF, Hall B, King E, Punwani J, Van Norman J, Sieburth LE (2003) VARICOSE, a WD-domain protein, is required for leaf blade development. Development 130(26):6577-6588. doi:10.1242/dev.00909

51. Sheth U, Parker R (2003) Decapping and decay of messenger RNA occur in cytoplasmic processing bodies. Science 300(5620):805-808. doi:10.1126/science. 1082320

52. Perea-Resa C, Hernandez-Verdeja T, Lopez-Cobollo R, del Mar Castellano M, Salinas J (2012) LSM proteins provide accurate splicing and decay of selected transcripts to ensure normal Arabidopsis development. Plant Cell 24(12):4930-4947. doi:10. $1105 /$ tpc. 112.103697

53. Golisz A, Sikorski PJ, Kruszka K, Kufel J (2013) Arabidopsis thaliana LSM proteins function in mRNA splicing and degradation. Nucleic Acids Res 41(12):6232-6249. doi:10.1093/nar/gkt296

54. Xu J, Chua NH (2009) Arabidopsis decapping 5 is required for mRNA decapping, P-body formation, and translational repression during postembryonic development. Plant Cell 21(10):3270-3279. doi:10.1105/tpc.109.070078

55. Zhang Z, Zhang S, Zhang Y, Wang X, Li D, Li Q, Yue M, Li Q, Zhang YE, Xu Y, Xue Y, Chong K, Bao S (2011) Arabidopsis floral initiator SKB1 confers high salt tolerance by regulating transcription and pre-mRNA splicing through altering histone H4R3 and small nuclear ribonucleoprotein LSM4 methylation. Plant Cell 23(1):396-411. doi:10.1105/tpc.110.081356

56. Cui P, Zhang S, Ding F, Ali S, Xiong L (2014) Dynamic regulation of genome-wide pre-mRNA splicing and stress tolerance by the Sm-like protein LSm5 in Arabidopsis. Genome Biol 15(1):R1. doi:10.1186/gb-2014-15-1-r1

57. Liu Q, Kasuga M, Sakuma Y, Abe H, Miura S, YamaguchiShinozaki K, Shinozaki K (1998) Two transcription factors, DREB1 and DREB2, with an EREBP/AP2 DNA binding domain separate two cellular signal transduction pathways in drought- and low-temperature-responsive gene expression, respectively, Arabidopsis. Plant Cell 10(8):1391-1406

58. Saedler R, Jakoby M, Marin B, Galiana-Jaime E, Hulskamp M (2009) The cell morphogenesis gene SPIRRIG in Arabidopsis encodes a WD/BEACH domain protein. Plant J 59(4):612-621. doi:10.1111/j.1365-313X.2009.03900.x

59. Kastenmayer JP, Green PJ (2000) Novel features of the XRNfamily in Arabidopsis: evidence that AtXRN4, one of several orthologs of nuclear Xrn2p/Rat1p, functions in the cytoplasm. Proc Natl Acad Sci USA 97(25):13985-13990. doi:10.1073/ pnas.97.25.13985

60. Souret FF, Kastenmayer JP, Green PJ (2004) AtXRN4 degrades mRNA in Arabidopsis and its substrates include selected miRNA targets. Mol Cell 15(2):173-183. doi:10.1016/j.molcel. 2004.06.006

61. Rymarquis LA, Souret FF, Green PJ (2011) Evidence that XRN4, an Arabidopsis homolog of exoribonuclease XRN1, preferentially impacts transcripts with certain sequences or in particular functional categories. RNA 17(3):501-511. doi:10. 1261/rna.2467911

62. Gazzani S, Lawrenson T, Woodward C, Headon D, Sablowski R (2004) A link between mRNA turnover and RNA interference in Arabidopsis. Science 306(5698):1046-1048. doi:10.1126/science. 1101092

63. Potuschak T, Vansiri A, Binder BM, Lechner E, Vierstra RD, Genschik P (2006) The exoribonuclease XRN4 is a component of the ethylene response pathway in Arabidopsis. Plant Cell 18(11):3047-3057. doi:10.1105/tpc.106.046508

64. Nguyen AH, Matsui A, Tanaka M, Mizunashi K, Nakaminami K, Hayashi M, Iida K, Toyoda T, Nguyen DV, Seki M (2015) Loss of Arabidopsis 5'-3' exoribonuclease AtXRN4 function enhances heat stress tolerance of plants subjected to severe heat stress. Plant Cell Physiol 56(9):1762-1772. doi:10.1093/pcp/pcv096

65. Chen H, Xiong L (2010) The bifunctional abiotic stress signalling regulator and endogenous RNA silencing suppressor FIERY1 is required for lateral root formation. Plant Cell Environ 33(12):2180-2190. doi:10.1111/j.1365-3040.2010.02218.x

66. Olmedo G, Guo H, Gregory BD, Nourizadeh SD, AguilarHenonin L, Li H, An F, Guzman P, Ecker JR (2006) ETHYLENE-INSENSITIVE5 encodes a $5^{\prime} \rightarrow 3^{\prime}$ exoribonuclease required for regulation of the EIN3-targeting F-box proteins EBF1/2. Proc Natl Acad Sci USA 103(36):13286-13293. doi:10.1073/pnas.0605528103

67. Merret R, Descombin J, Juan YT, Favory JJ, Carpentier MC, Chaparro C, Charng YY, Deragon JM, Bousquet-Antonelli C (2013) XRN4 and LARP1 are required for a heat-triggered mRNA decay pathway involved in plant acclimation and survival during thermal stress. Cell Rep 5(5):1279-1293. doi:10. 1016/j.celrep.2013.11.019

68. Bousquet-Antonelli C, Deragon JM (2009) A comprehensive analysis of the La-motif protein superfamily. RNA 15(5):750-764. doi:10.1261/rna.1478709

69. Hu W, Sweet TJ, Chamnongpol S, Baker KE, Coller J (2009) Co-translational mRNA decay in Saccharomyces cerevisiae. Nature 461(7261):225-229. doi:10.1038/nature08265

70. Sement FM, Ferrier E, Zuber H, Merret R, Alioua M, Deragon JM, Bousquet-Antonelli C, Lange H, Gagliardi D (2013) Uridylation prevents $3^{\prime}$ trimming of oligoadenylated mRNAs. Nucleic Acids Res 41(14):7115-7127. doi:10.1093/nar/gkt465

71. Merret R, Nagarajan VK, Carpentier MC, Park S, Favory JJ, Descombin J, Picart C, Charng YY, Green PJ, Deragon JM, Bousquet-Antonelli C (2015) Heat-induced ribosome pausing triggers mRNA co-translational decay in Arabidopsis thaliana. Nucleic Acids Res 43(8):4121-4132. doi:10.1093/nar/gkv234

72. Sweet T, Kovalak C, Coller J (2012) The DEAD-box protein Dhh1 promotes decapping by slowing ribosome movement. PLoS Biol 10(6):e1001342. doi:10.1371/journal.pbio.1001342

73. Xiong L, Gong Z, Rock CD, Subramanian S, Guo Y, Xu W, Galbraith D, Zhu JK (2001) Modulation of abscisic acid signal transduction and biosynthesis by an Sm-like protein in Arabidopsis. Dev Cell 1(6):771-781

74. Kong X, Ma L, Yang L, Chen Q, Xiang N, Yang Y, Hu X (2014) Quantitative proteomics analysis reveals that the nuclear capbinding complex proteins arabidopsis CBP20 and CBP80 modulate the salt stress response. J Proteome Res 13(5):2495-2510. doi:10.1021/pr4012624

75. Papp I, Mur LA, Dalmadi A, Dulai S, Koncz C (2004) A mutation in the Cap Binding Protein 20 gene confers drought tolerance to Arabidopsis. Plant Mol Biol 55(5):679-686. doi:10. 1007/s11103-004-1680-2

76. Hugouvieux V, Kwak JM, Schroeder JI (2001) An mRNA cap binding protein, $\mathrm{ABH} 1$, modulates early abscisic acid signal transduction in Arabidopsis. Cell 106(4):477-487

77. Zhu JK (2002) Salt and drought stress signal transduction in plants. Annu Rev Plant Biol 53:247-273. doi:10.1146/annurev. arplant.53.091401.143329

78. Kuhn JM, Schroeder JI (2003) Impacts of altered RNA metabolism on abscisic acid signaling. Curr Opin Plant Biol 6(5):463-469

79. Kawa D, Julkowska M, Montero Sommerfeld H, At Horst, Haring MA, Testerink C (2016) Phosphate-dependent root system architecture responses to salt stress. Plant Physiol. doi:10. 1104/pp.16.00712

80. Iwakawa HO, Tomari Y (2015) The functions of microRNAs: mRNA decay and translational repression. Trends Cell Biol 25(11):651-665. doi:10.1016/j.tcb.2015.07.011 
81. Gy I, Gasciolli V, Lauressergues D, Morel JB, Gombert J, Proux F, Proux C, Vaucheret H, Mallory AC (2007) Arabidopsis FIERY1, XRN2, and XRN3 are endogenous RNA silencing suppressors. Plant Cell 19(11):3451-3461. doi:10.1105/tpc.107. 055319

82. Covarrubias AA, Reyes JL (2010) Post-transcriptional gene regulation of salinity and drought responses by plant microRNAs. Plant Cell Environ 33(4):481-489. doi:10.1111/j.13653040.2009.02048.x

83. Ding Y, Tao Y, Zhu C (2013) Emerging roles of microRNAs in the mediation of drought stress response in plants. J Exp Bot 64(11):3077-3086. doi:10.1093/jxb/ert164

84. Zhang JF, Yuan LJ, Shao Y, Du W, Yan DW, Lu YT (2008) The disturbance of small RNA pathways enhanced abscisic acid response and multiple stress responses in Arabidopsis. Plant Cell Environ 31(4):562-574. doi:10.1111/j.1365-3040. 2008.01786.x

85. Bogamuwa SP, Jang JC (2014) Tandem CCCH zinc finger proteins in plant growth, development and stress response. Plant Cell Physiol 55(8):1367-1375. doi:10.1093/pcp/pcu074

86. Guo YH, Yu YP, Wang D, Wu CA, Yang GD, Huang JG, Zheng CC (2009) GhZFP1, a novel CCCH-type zinc finger protein from cotton, enhances salt stress tolerance and fungal disease resistance in transgenic tobacco by interacting with GZIRD21A and GZIPR5. New Phytol 183(1):62-75. doi:10.1111/j.14698137.2009.02838.x

87. Lykke-Andersen J, Wagner E (2005) Recruitment and activation of mRNA decay enzymes by two ARE-mediated decay activation domains in the proteins TTP and BRF-1. Genes Dev 19(3):351-361. doi:10.1101/gad.1282305

88. Fabian MR, Frank F, Rouya C, Siddiqui N, Lai WS, Karetnikov A, Blackshear PJ, Nagar B, Sonenberg N (2013) Structural basis for the recruitment of the human CCR4-NOT deadenylase complex by tristetraprolin. Nat Struct Mol Biol 20(6):735-739. doi: $10.1038 / \mathrm{nsmb} .2572$

89. Jan A, Maruyama K, Todaka D, Kidokoro S, Abo M, Yoshimura E, Shinozaki K, Nakashima K, Yamaguchi-Shinozaki K (2013) OsTZF1, a CCCH-tandem zinc finger protein, confers delayed senescence and stress tolerance in rice by regulating stress-related genes. Plant Physiol 161(3):1202-1216. doi:10.1104/pp. 112.205385

90. Pomeranz MC, Hah C, Lin PC, Kang SG, Finer JJ, Blackshear PJ, Jang JC (2010) The Arabidopsis tandem zinc finger protein AtTZF1 traffics between the nucleus and cytoplasmic foci and binds both DNA and RNA. Plant Physiol 152(1):151-165. doi:10.1104/pp.109.145656

91. Lee SJ, Jung HJ, Kang H, Kim SY (2012) Arabidopsis zinc finger proteins AtC3H49/AtTZF3 and AtC3H20/AtTZF2 are involved in ABA and JA responses. Plant Cell Physiol 53(4):673-686. doi:10.1093/pcp/pcs023

92. Qu J, Kang SG, Wang W, Musier-Forsyth K, Jang JC (2014) The Arabidopsis thaliana tandem zinc finger 1 (AtTZF1) protein in RNA binding and decay. Plant J 78(3):452-467. doi:10.1111/ tpj. 12485

93. Sun J, Jiang H, Xu Y, Li H, Wu X, Xie Q, Li C (2007) The $\mathrm{CCCH}$-type zinc finger proteins AtSZF1 and AtSZF2 regulate salt stress responses in Arabidopsis. Plant Cell Physiol 48(8):1148-1158. doi:10.1093/pcp/pcm088

94. Huang P, Ju H-W, Min J-H, Zhang X, Chung J-S, Cheong H-S, Kim CS (2012) Molecular and physiological characterization of the Arabidopsis thaliana oxidation-related zinc finger 2, a plasma membrane protein involved in $\mathrm{ABA}$ and salt stress response through the ABI2-mediated signaling pathway. Plant Cell Physiol 53(1):193-203. doi:10.1093/pcp/pcr162

95. Franks TM, Lykke-Andersen J (2007) TTP and BRF proteins nucleate processing body formation to silence mRNAs with AU- rich elements. Genes Dev 21(6):719-735. doi:10.1101/gad. 1494707

96. Bogamuwa S, Jang JC (2016) Plant tandem CCCH zinc finger proteins interact with $\mathrm{ABA}$, drought, and stress response regulators in processing-bodies and stress granules. PLoS One 11 (3):e0151574. doi:10.1371/journal.pone.0151574

97. Rzeczkowski K, Beuerlein K, Muller H, Dittrich-Breiholz O, Schneider H, Kettner-Buhrow D, Holtmann H, Kracht M (2011) c-Jun N-terminal kinase phosphorylates DCP1a to control formation of P bodies. J Cell Biol 194(4):581-596. doi:10.1083/ jcb.201006089

98. Yoon JH, Choi EJ, Parker R (2010) Dcp2 phosphorylation by Ste20 modulates stress granule assembly and mRNA decay in Saccharomyces cerevisiae. J Cell Biol 189(5):813-827. doi:10. 1083/jcb.200912019

99. Roux ME, Rasmussen MW, Palma K, Lolle S, Regue AM, Bethke G, Glazebrook J, Zhang W, Sieburth L, Larsen MR, Mundy J, Petersen M (2015) The mRNA decay factor PAT1 functions in a pathway including MAP kinase 4 and immune receptor SUMM2. EMBO J 34(5):593-608. doi:10.15252/embj. 201488645

100. Boudsocq M, Barbier-Brygoo H, Lauriere C (2004) Identification of nine sucrose nonfermenting 1-related protein kinases 2 activated by hyperosmotic and saline stresses in Arabidopsis thaliana. J Biol Chem 279(40):41758-41766. doi:10.1074/jbc. M405259200

101. Lee SC, Lan W, Buchanan BB, Luan S (2009) A protein kinasephosphatase pair interacts with an ion channel to regulate ABA signaling in plant guard cells. Proc Natl Acad Sci USA 106(50):21419-21424. doi:10.1073/pnas.0910601106

102. Geiger D, Scherzer S, Mumm P, Stange A, Marten I, Bauer H, Ache P, Matschi S, Liese A, Al-Rasheid KA, Romeis T, Hedrich $\mathrm{R}$ (2009) Activity of guard cell anion channel SLAC1 is controlled by drought-stress signaling kinase-phosphatase pair. Proc Natl Acad Sci USA 106(50):21425-21430. doi:10.1073/pnas. 0912021106

103. Sato A, Sato Y, Fukao Y, Fujiwara M, Umezawa T, Shinozaki K, Hibi T, Taniguchi M, Miyake H, Goto DB, Uozumi N (2009) Threonine at position 306 of the KAT1 potassium channel is essential for channel activity and is a target site for ABA-activated SnRK2/OST1/SnRK2.6 protein kinase. Biochem J 424(3):439-448. doi:10.1042/BJ20091221

104. Sirichandra C, Gu D, Hu HC, Davanture M, Lee S, Djaoui M, Valot B, Zivy M, Leung J, Merlot S, Kwak JM (2009) Phosphorylation of the Arabidopsis AtrbohF NADPH oxidase by OST1 protein kinase. FEBS Lett 583(18):2982-2986. doi:10. 1016/j.febslet.2009.08.033

105. Grondin A, Rodrigues O, Verdoucq L, Merlot S, Leonhardt N, Maurel C (2015) Aquaporins contribute to ABA-triggered stomatal closure through OST1-mediated phosphorylation. Plant Cell 27(7):1945-1954. doi:10.1105/tpc.15.00421

106. Furihata T, Maruyama K, Fujita Y, Umezawa T, Yoshida R, Shinozaki K, Yamaguchi-Shinozaki K (2006) Abscisic aciddependent multisite phosphorylation regulates the activity of a transcription activator AREB1. Proc Natl Acad Sci USA 103(6):1988-1993. doi:10.1073/pnas.0505667103

107. McLoughlin F, Galvan-Ampudia CS, Julkowska MM, Caarls L, van der Does D, Lauriere C, Munnik T, Haring MA, Testerink C (2012) The Snf1-related protein kinases SnRK2.4 and SnRK2.10 are involved in maintenance of root system architecture during salt stress. Plant J. doi:10.1111/j.1365-313X.2012.05089.x

108. Ovecka M, Takac T, Komis G, Vadovic P, Bekesova S, Doskocilova A, Samajova V, Luptovciak I, Samajova O, Schweighofer A, Meskiene I, Jonak C, Krenek P, Lichtscheidl I, Skultety L, Hirt H, Samaj J (2014) Salt-induced subcellular kinase relocation and seedling susceptibility caused by 
overexpression of Medicago SIMKK in Arabidopsis. J Exp Bot 65(9):2335-2350. doi:10.1093/jxb/eru115

109. Julkowska MM, McLoughlin F, Galvan-Ampudia CS, Rankenberg JM, Kawa D, Klimecka M, Haring MA, Munnik T, Kooijman EE, Testerink C (2015) Identification and functional characterization of the Arabidopsis Snf1-related protein kinase SnRK2.4 phosphatidic acid-binding domain. Plant Cell Environ 38(3):614-624. doi:10.1111/pce.12421

110. de la Fuente van Bentem S, Anrather D, Roitinger E, Djamei A, Hufnagl T, Barta A, Csaszar E, Dohnal I, Lecourieux D, Hirt H
(2006) Phosphoproteomics reveals extensive in vivo phosphorylation of Arabidopsis proteins involved in RNA metabolism. Nucleic Acids Res 34(11):3267-3278. doi:10.1093/nar/gk1429

111. Kohler A, Hurt E (2007) Exporting RNA from the nucleus to the cytoplasm. Nat Rev Mol Cell Biol 8(10):761-773. doi:10.1038/ nrm2255

112. Tarun SZ Jr, Sachs AB (1996) Association of the yeast poly(A) tail binding protein with translation initiation factor eIF4G. EMBO J 15(24):7168-7177 